\title{
New Transfer Functions for Correcting Turbulent Water Vapour Fluxes
}

\author{
A. De Ligne - B. Heinesch • M. Aubinet
}

Received: 30 March 2009 / Accepted: 6 July 2010 / Published online: 17 July 2010

(C) Springer Science+Business Media B.V. 2010

\begin{abstract}
We address the problem of the high-frequency correction of water vapour fluxes measured by eddy covariance with a closed-path infrared gas analyser (IRGA). Different transfer functions are compared and evaluated at a forested (Vielsalm, Belgium) and an agricultural (Lonzée, Belgium) site. Classical functions, usually applied to correct $\mathrm{CO}_{2}$ fluxes (Gaussian, Lorentzian), are found to be unsuited to water vapour cospectral corrections, being characterised by too sharp a decrease at high frequency. Two other functions characterised by a lower decreasing slope are found to better fit experimental transfer functions. They were calibrated and validated on experimental transfer functions and their dependency on air humidity is parameterised. On this basis, new correction coefficients are estimated. The coefficients are found to be larger than those based on the classical functions, even when the dependency of the latter on air humidity is taken into account. The difference amounts to $10 \%$ at the forested site and to $5 \%$ larger at the crop site. The study highlights the necessity of characterising the water transfer function shape and taking it into account in the correction factor at each site equipped with a closed path IRGA.
\end{abstract}

Keywords Eddy covariance · High frequency correction · Transfer functions · Water vapour fluxes

\section{Abbreviation}

RMSD Root-mean-square differences

\section{List of symbols}

$a_{j} \quad$ Parameter of regression for model $j$

$b_{j} \quad$ Parameter of regression for model $j$

C Cospectrum

\footnotetext{
A. De Ligne $(\varangle) \cdot$ B. Heinesch · M. Aubinet Gembloux Agro-Bio Tech, University of Liege, Unité de Physique des Biosystèmes, 8 Avenue de la Faculté, 5030 Gembloux, Belgium e-mail: deligne.a@gmail.com
} 
$C_{\text {ref }} \quad$ Cospectrum of reference

$C_{w s} \quad$ Cospectral density of two variables $w$ and $s$

$C_{w s}^{\exp } \quad$ Experimental cospectral density of two variables $w$ and $s$

$C_{w T} \quad$ STF cospectral density

$C_{w T}^{\exp } \quad$ Experimental STF cospectral density

c $\quad \mathrm{CO}_{2}$ concentration

$D_{s} \quad$ Vapour pressure deficit

$d_{j} \quad$ Parameter of regression for model $j$

$f \quad$ Frequency

$f_{o} \quad$ Half-power frequency

$f_{o, s, j} \quad$ Half-power frequency for a scalar $s$ and for model $j$

$g_{j} \quad$ Parameter of regression for model $j$

$h \quad$ Water vapour concentration

$i_{j} \quad$ Parameter of regression for model $j$

$j \quad$ Number of models

$k_{j} \quad$ Parameter of regression for model $j$

$L_{\text {self }} \quad$ Inductance

$N_{T, \exp }$ Normalisation factor of the measured STF cospectrum

$N_{s} \quad$ Normalisation factors of the cospectrum of variables $w$ and $s$

$N_{s, \exp } \quad$ Normalisation factors of the measured cospectrum of variables $w$ and $s$

$s \quad$ Scalar

$x_{j} \quad$ Exponent-parameter of model $j$

$w \quad$ Vertical wind speed

$w^{\prime} \quad$ Fluctuation of the vertical wind speed

$\delta_{s} \quad$ Transfer function of the scalar $s$

$\delta_{s}^{\exp } \quad$ Experimental transfer function of the scalar $s$

$\varepsilon_{s} \quad$ Correction factor for the flux of scalar $s$

\section{Introduction}

Eddy-covariance measurements are being made more and more widely in order to evaluate energy, momentum, water vapour, carbon dioxide and other scalar fluxes at the ecosystem scale (Baldocchi 2003). As with all methods, eddy covariance is affected by random and systematic biases that should be identified and reduced.

High-frequency fluctuation reduction is one of these well-known systematic errors, and is especially important when tracer concentrations are measured with a closed-path infrared gas analyser (IRGA) (Moore 1986; Aubinet et al. 2000; Massman 2000; Clement 2004). The major problem derives from the transport of air from the sampling point to the analyser, when air is partially mixed in the filters and in the tube. The high-frequency loss associated with this process has been analysed, notably by Eugster and Senn (1995), Leuning and Judd (1996), Moncrieff et al. (1997), Massman (2000) and Aubinet et al. (2001), who quantified the high-frequency attenuation with a transfer function.

The present study focuses on the transfer function characterising water vapour fluxes measured with a closed-path analyzer. An exact determination of water vapour fluxes is necessary to improve the precision of a site's water balance and to better estimate ecosystem water-use efficiency. Precise water vapour flux estimates are also needed when these fluxes obtained with a classical eddy-covariance system are used as a benchmark to test the validity 
of less established systems; for example, if water vapour fluxes obtained with traditional eddy covariance and with proton transfer reaction mass spectrometry are compared to assess the validity of the latter technique (Ammann et al. 2006). To make this possible, it is essential to obtain a reliable estimate of the eddy-covariance water vapour flux.

The problem is that the transfer functions established for $\mathrm{CO}_{2}$ fluxes, if well suited for this purpose, do not satisfactorily describe the water vapour fluctuation attenuation. Indeed, in addition to air mixing, water vapour particles undergo additional sorption/desorption on tube walls and filters (Leuning and Judd 1996; Clement 2004; Ibrom et al. 2007; Massman and Ibrom 2008). As a result the transfer function for water vapour may depend on air humidity. Modified Lorentzian and Gaussian functions, which take transfer function dependence on water vapour into account, were thus proposed by Ibrom et al. (2007) and Mammarella et al. (2009). Mammarella et al. (2009) also suggested that this dependence is exacerbated by the tube contamination. We show in this paper that even these modified functions do not fit the experimental transfer functions at our sites. Indeed, we found that the observed transfer functions decreased less steeply than the classical ones and that their decrease begins at lower frequencies.

Consequently, we propose new transfer functions that better fit our experimental results. We calibrate and validate these functions on measurements made at a forested (Vielsalm) and an agricultural (Lonzée) site. We then discuss their dependence on atmospheric humidity and their impact on water vapour flux correction factors.

\section{Site and Materials}

Measurements were made in Belgium at two sites: a forested site, Vielsalm $\left(50^{\circ} 18^{\prime} \mathrm{N}\right.$, $\left.6^{\circ} 00^{\prime} \mathrm{E}\right)$ and an agricultural site, Lonzée ( $\left.50^{\circ} 33^{\prime} 08^{\prime \prime} \mathrm{N}, 4^{\circ} 44^{\prime} 42^{\prime \prime} \mathrm{E}\right)$. Measurements began in September 1996 at Vielsalm and in April 2004 at Lonzée, and at the time of writing continue at both sites. A description of the Vielsalm and Lonzée sites was provided by Laitat et al. (2000) and Moureaux et al. (2006), respectively.

The forest in Vielsalm is comprised of two major species: Douglas fir (Pseudotsuga menziesii [Mirb.] Franco) with 49 stems ha $^{-1}$ and beech (Fagus sylvatica L.) with 145 stems $\mathrm{ha}^{-1}$; these two species represent more than $80 \%$ of the mixed ecosystem and form two respective sub-plots. The remainder is made up of a variety of species (silver fir, Norway spruce, Scots pine, pedonculate oak). The eddy-covariance system was installed on a tower, at a height of $40 \mathrm{~m}$ above the ground. The zero-plane displacement height was estimated at $28.5 \mathrm{~m}$. At Lonzée, measurements were made at a height of $2.7 \mathrm{~m}$ above a traditionally managed crop with a 4-year rotation cycle (sugar beet, winter wheat, seed potato and winter wheat) (Aubinet et al. 2009). Each eddy-covariance system measured $\mathrm{CO}_{2}$, sensible and latent heat fluxes; details of the systems are given in Appendix 1.

\section{Theory}

\subsection{Eddy-Covariance Spectral Analysis}

A first theoretical description of fluctuation attenuation by eddy-covariance systems was first proposed by Moore (1986) who listed the different processes responsible for attenuation and provided a specific transfer function. The eddy-covariance system transfer function was then considered as the product of each specific function. Attenuation results from the 
dynamic frequency responses of the sonic anemometer and the IRGA, from sensor response mismatch, from scalar path averaging, from sensor separation (Moore 1986), and from the attenuation of the concentration fluctuations down the sampling tube. This last attenuation is typical of closed-path systems. Specific transfer functions describing the impact of fluctuation attenuation in tubes have been adapted by Leuning and Moncrieff (1990), Lenschow and Raupach (1991), Massman (1991), Leuning and King (1992), Leuning and Judd (1996) and Moncrieff et al. (1997). With this formalism, the real $\left(\overline{w^{\prime} s^{\prime}}\right)$ and measured $\left(\overline{w^{\prime} s^{\prime}}\right.$ meas $)$ covariances of the vertical wind velocity component $(w)$ and the scalar mixing ratio $(s)$ are written, respectively, as:

$$
\begin{aligned}
\overline{w^{\prime} s^{\prime}} & =\int_{0}^{\infty} C_{w s}(f) d f, \\
\overline{w^{\prime} s^{\prime}} \text { meas } & =\int_{0}^{\infty} \delta_{s}(f) C_{w s}(f) d f,
\end{aligned}
$$

where $C_{w s}(f)$ represents the cospectral density of the real signal and $\delta_{s}(f)$ is the transfer function characteristic of the measurement system. In the following, water vapour mixing ratio is represented by $h$, and the $\mathrm{CO}_{2}$ mixing ratio by $c$. Under these conditions, the relative error affecting the eddy-covariance measurements can be estimated as the ratio of the second to the first integral, and, conversely, the correction factor denoted $\varepsilon_{s}$ as the inverse ratio:

$$
\varepsilon_{s}=\frac{\int_{0}^{\infty} C_{w s}(f) d f}{\int_{0}^{\infty} \delta_{s}(f) C_{w s}(f) d f} .
$$

Equation 3 may be used to evaluate the correction factor so long as the transfer function $\delta_{s}(f)$ and the ideal cospectrum (i.e. the cospectrum that would have been observed in the absence of an instrumental bias, $C_{w s}$ ) are known.

In practice, $\delta_{s}(f)$ is computed as the ratio of the measured cospectrum to the ideal cospectrum following:

$$
\delta_{s}^{\exp }(f)=\frac{N_{s} C_{w s}^{\exp }(f)}{N_{s, \exp } C_{w s}(f)},
$$

where $C_{w s}^{\exp }$ is the experimental cospectrum for the scalar $s$, and $N_{s}$ and $N_{s \text {, exp }}$ are, respectively, the normalisation factors of the ideal and experimental cospectra of the variables $w$ and $s$. These factors are deduced from a comparison between the low frequency parts of the cospectra (Aubinet et al. 2000) and are discussed later.

Implementations of the computation of the transfer function (Eq. 4) and of the correction factor (Eq. 3) require an estimation of the undamped cospectrum of $w$ and the scalar $s$. However, as this is not available, a substitute must be obtained. Aubinet et al. (2000, 2001) proposed using the sonic temperature flux (STF) cospectrum normalised accordingly to this aim. With this approach, $\delta_{s}^{\exp }$ can be estimated as:

$$
\delta_{s}^{\exp }(f)=\frac{N_{T, \exp } C_{w s}^{\exp }(f)}{N_{s, \exp } C_{w T}^{\exp }(f)},
$$

where $C_{w T}^{\exp }$ is the experimental cospectrum for the STF and $N_{T \text {,exp }}$ are its normalisation factors. The STF is deduced directly from sonic anemometer measurements as the covariance of the sonic temperature and vertical velocity fluctuations. It is close to the sensible heat flux in 
magnitude, but differs slightly from it, since it is computed on the basis of sonic temperature rather than air temperature, and thus contains a contribution from the water vapour flux.

The normalisation factors $N_{T \text {,exp }}$ and $N_{s, \exp }$ should correspond to values of the covariance $\overline{w^{\prime} T^{\prime}}$ or $\overline{w^{\prime} s^{\prime}}$, respectively. However, as the measured covariance is affected by high frequency attenuation, we rather calculate them as:

$$
\frac{N_{T, \exp }}{N_{s, \exp }}=\frac{\int_{0}^{f^{\prime}} C_{w T}^{\exp }(f) d f}{\int_{0}^{f^{\prime}} C_{w s}^{\exp }(f) d f},
$$

where the limit frequency, $f^{\prime}$, is high enough to allow computation of the normalisation factor with sufficient precision, and low enough to not be affected by high frequency attenuation (Aubinet et al. 2000).

The use of the STF cospectrum to compute the system transfer function implies: firstly, that there is similarity between both transports and sources of sensible heat and of water vapour, and secondly, that the high frequency attenuation of the STF cospectral density is negligible compared with that affecting the $\mathrm{CO}_{2}$ and water vapour fluxes. Similarity between transport processes was proposed notably by Wyngaard and Coté (1972), Panofsky and Dutton (1984) and Ohtaki (1985), and it has been widely used in spectral correction schemes. It has been tested above forests by various authors (Anderson et al. 1986; Monji et al. 1994; Ruppert et al. 2006) who found high scalar similarity around the midday period. A general substantiation of this hypothesis remains however lacking. The similarity between sources appears quite reasonable at both sites since the sources of both fluxes (soil and leaves) are identical. The second hypothesis means explicitly that fluctuation attenuation due to electronic response time or path averaging (at not too high wind speeds) takes place at much higher frequencies than attenuation due to mixing in the tube and from sorption/desorption. Moncrieff et al. (1997) have shown that the theoretical transfer functions for the electronic response time and path averaging of the commonly used sonic anemometers show almost no attenuation below $1 \mathrm{~Hz}$ and limited attenuation between 1 and $10 \mathrm{~Hz}$. In contrast, attenuation due to mixing in the tube and from sorption/desorption occurs at much lower frequencies, as will be shown later. Aubinet et al. $(2000,2001)$ confirmed that this result was valid in most eddy-covariance measurement systems including those used in the present study. Generally, two types of equations are fitted to these experimental transfer functions: Gaussian (Aubinet et al. 2001):

$$
\delta_{S}(f)=\exp \left[-\ln (2)\left(\frac{f}{f_{o, s}}\right)^{2}\right]
$$

and Lorentzian (Eugster and Senn 1995):

$$
\delta_{s}(f)=\frac{1}{1+\left(\frac{f}{f_{o, s}}\right)^{2}} .
$$

In both equations, $f$ represents the natural frequency and $f_{o, s}$ the half-power frequency for a scalar $s$ (i.e., the frequency at which the transfer function equals 0.5).

Equation 8 can also be considered as characteristic of a first-order filter performed by an $\mathrm{RL}$ circuit of unitary resistance and inductance equal to $L_{\text {self }}\left[\mathrm{Hz}^{-1}\right]$. Under these conditions, the filter inductance is related to the half-power frequency by:

$$
f_{o, s}=\frac{1}{2 \pi L_{\mathrm{self}}},
$$


an equation that is widely used, for example by Horst (1997), Su et al. (2004), Ibrom et al. (2007), Hiller et al. (2008) and Mammarella et al. (2009).

\subsection{Studies on Water Vapour Fluxes}

As the procedure described above is usually applied to correct $\mathrm{CO}_{2}$ fluxes, few studies have been made on the transfer functions for water vapour. Until recently, corrections for water vapour were applied by following the same steps as for $\mathrm{CO}_{2}$ and adapting a constant halfpower frequency. Recent studies on reactive tracer measurements have shown that $\delta_{h}$ depends on atmospheric conditions. A correlation between its half-power frequency and air humidity was found by Clement (2004) who hypothesized that the extra attenuation of water vapour fluctuations was related to sorption/desorption on the tube wall. Ibrom et al. (2007) and Mammarella et al. (2009) confirmed that the fluctuation attenuation increased sharply with increasing relative humidity. Ibrom et al. (2007) proposed a parameterisation of this response and calibrated it for their system, while Mammarella et al. (2009) showed in addition that this response was related to the lack of tube cleanliness. Their study, however, was specific to one site equipped with a system without filters at the sampling tube inlet, which would induce more rapid tube contamination than for sites equipped with filters. Massman and Ibrom (2008) studied fluxes of passive and active tracers. For passive tracers, they established new formulations of tube flow dynamics, and for active tracers, the attenuation of water vapour fluctuations is represented by a new "physically-based semi-empirical model". With models of different phenomena, they proposed one analytical expression combining concentration fluctuation attenuation due to air transport and to humidity.

\section{Method}

\subsection{General Procedure}

The STF, $\mathrm{CO}_{2}$ and water vapour cospectral densities were computed for each selected sample and the experimental transfer functions $\left(\delta^{\exp }\right)$ for water vapour and $\mathrm{CO}_{2}$ were deduced by computing the normalised ratio of the corresponding cospectra to the STF cospectra, using a limit frequency $f^{\prime}$ of $0.01 \mathrm{~Hz}$. For each individual $\delta^{\exp }$, the theoretical equations were adjusted by a least squares regression, giving a so-called adjusted transfer function and also adjusted regression parameters. The response of the adjusted parameters to climatic variables was again parameterised. A modelled transfer function was then built on the basis of the preceding theoretical equations in which parameters were estimated from their climatic response. This model was validated by computing the root-mean-square differences (RMSD) between modelled and experimental transfer functions for each sample of the validation set. The validation was performed separately for different vapour pressure deficit $\left(D_{s}\right)$ categories. The cospectral densities were computed using the Eddysoft software (Kolle and Rebmann 2007) and all parameters optimizations were achieved using Matlab, R2007a (The MathWorks, Inc., Natick, MA, USA). More details about the procedure are given below.

\subsection{Data Selection}

Measurements taken from September 1996 to November 2008 at the Vielsalm site and from April 2004 to November 2008 at the Lonzée site were selected in order to obtain well-defined 
Table 1 Number of samples at the Vielsalm site for each category of vapour pressure deficit $\left(D_{S}\right)$ for the calibration dataset $(\mathrm{Cal})$ and the validation dataset (Val)

\begin{tabular}{lrr}
\hline$D_{s}$ categories $(\mathrm{Pa})$ & $\mathrm{Cal}$ & Val \\
\hline $0-500$ & 4 & 7 \\
$500-1,000$ & 89 & 88 \\
$1,000-1,500$ & 72 & 71 \\
$>1,500$ & 60 & 63 \\
Total & 225 & 229 \\
\hline
\end{tabular}

\begin{tabular}{lrr}
\hline$D_{s}$ categories $(\mathrm{Pa})$ & $\mathrm{Cal}$ & $\mathrm{Val}$ \\
\hline $0-500$ & 76 & 77 \\
$500-1,000$ & 104 & 120 \\
$1,000-1,500$ & 55 & 38 \\
$>1,500$ & 33 & 32 \\
Total & 268 & 267 \\
\hline
\end{tabular}

Table 2 Same as Table 1 for the Lonzée site

cospectra. Each sample used for cospectral analysis was made up of six consecutive 30-min periods with sensible and latent heat fluxes both larger than $25 \mathrm{~W} \mathrm{~m}^{-2}$ and $\mathrm{CO}_{2}$ fluxes lower than $-2 \mu \mathrm{molm}^{-2} \mathrm{~s}^{-1}$ (Mammarella et al. 2009). A stationarity screening was also performed after Foken and Wichura (1996). Data with air humidity variability that was too large were excluded. The selection criterion was based on the standard deviation of the vapour pressure deficit $(>300 \mathrm{~Pa})$. The resulting selection was then divided into two datasets with alternated samples, one dataset for calibration and the other for validation. The number of remaining samples for each model is displayed in Tables 1 and 2 for both sites.

\subsection{Adjusted Transfer Function}

Four theoretical relations were chosen to fit $\delta^{\exp }$, and are given in Fig. 1. The first two are the Gaussian (Eq. 7, Fig. 1a) and Lorentzian (Eq. 8, Fig. 1b) equations given earlier and commonly used to characterise the transfer function of $\mathrm{CO}_{2}$. They will be referred hereafter as $\delta_{s, 1}$ and $\delta_{s, 2}$, respectively. In Fig. 1, the Gaussian equation is represented by a solid line, enabling a comparison to be made with the other relations. The two other relations were chosen for their ability to better fit the water vapour transfer function and are referred hereafter as $\delta_{s, 3}$ and $\delta_{s, 4}$, respectively. The first is similar to a Gaussian (Eq. 7) in which the value 2 of the exponent is replaced with an adjustable parameter, $x_{3}$ :

$$
\delta_{h, 3}(f)=\exp \left[-\ln (2)\left(\frac{f}{f_{o, h, 3}}\right)^{x_{3}}\right]
$$

The adjustable parameters are $f_{o, h, 3}$, the half-power frequency and $x_{3}$, the exponent.

The second relation derives from a product of the Gaussian equation, $\delta_{c, 1}$ and a specific transfer function characterised by a different adjustable half-power frequency $\left(f_{o, h, 4}\right)$ and an adjustable exponent $\left(x_{4}\right)$. This latter transfer function represents the process of water vapour sorption/desorption on hydrophilic particles on tube walls and on filters, and depends on air humidity: 

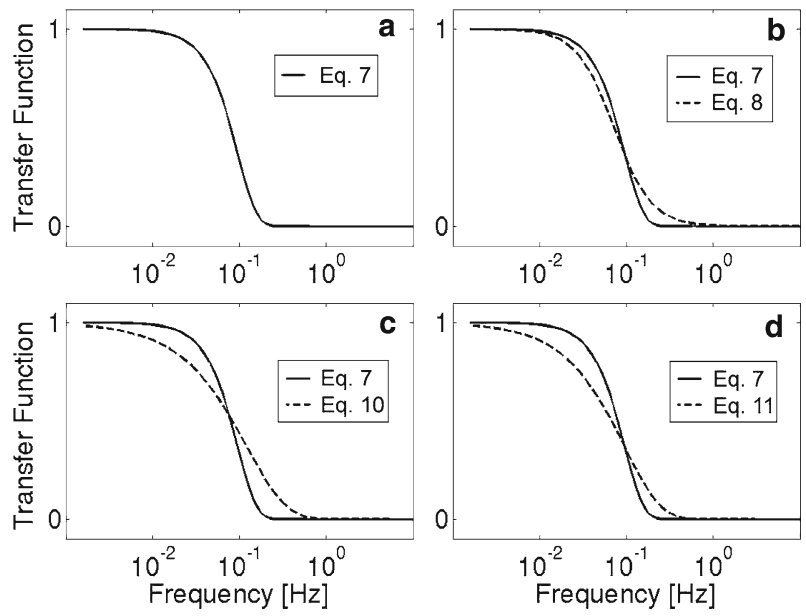

Fig. 1 Representation of different relations for the transfer functions adjusted for a wet day (250 Pa); Eq. 7 (Aubinet et al. 2000): solid line, reproduced in the three other plots; Eq. 8 (Eugster and Senn 1995), Eqs. 10 and 11 suggested in this paper: dashed line

$$
\delta_{h, 4}(f)=\exp \left(-\ln (2)\left(\frac{f}{f_{o, c, 4}}\right)^{2}-\ln (2)\left(\frac{f}{f_{o, h, 4}}\right)^{x_{4}}\right) .
$$

In addition, in Eq. 11 the half-power frequency for $\delta_{c, 1}\left(f_{o, c, 4}\right)$ constitutes a third parameter adjusted on $\delta_{c}^{\exp }$. In practice, at the Vielsalm site, $x_{4}$ was generally less than 2 , suggesting that $\delta_{h}$ has a lower slope than $\delta_{c}$. This function is referred to hereafter as $\delta_{h, 4}$. The two latter relations are shown in Fig. 1c and d, respectively.

\subsection{Climatic Dependence of Parameters}

We tested the parameter response to different climatic variables and found that the only variable causing significant dependence was air humidity. Water vapour pressure deficit $\left(D_{s}\right)$ was used to characterise air humidity because it provides a better regression with $f_{o, h}$ than does relative humidity. Apart from when clear non-linear behaviour was evident, the relationships between half-power frequencies, or exponent $x$, and $D_{s}$ were fitted using linear relationships of the type:

$$
\begin{aligned}
f_{o, h, j} & =a_{j} D_{s}+b_{j}, \\
x_{j} & =g_{j} D_{s}+i_{j} .
\end{aligned}
$$

This was the case for all models except for $\delta_{h, 4}$ (Eq. 11) at Lonzée, where a power function was used for $f_{o, h, 4}$ and at Vielsalm for $\delta_{h, 4}$ where an exponential was used for $x_{4}$ :

$$
\begin{aligned}
f_{o, h, 4} & =a_{4} D_{s}^{d_{4}}+b_{4}, \\
x_{4} & =g_{4} e^{\left(-k_{4} D_{s}\right)}+i_{4} .
\end{aligned}
$$

In Eqs. 11-14, $a_{j}, b_{j}, d_{j}, g_{j}, i_{j}, k_{j}$ are the adjustable parameters that refer to the modelled $\delta_{h, j}$. Despite the first data screening, several transfer functions could not be fitted by theoretical equations or had a fit that led to unlikely parameter values. This often occurred because the variability of the cospectral density was extremely large at high frequencies. The impact 
of extreme parameter values was reduced by a robust fitting using a weight vector (bisquare estimators; Cohen et al. 2003).

\subsection{Validation}

The validation was performed by comparing modelled with experimental transfer functions in different $D_{s}$ classes. The validation set was divided into different $D_{s}$ categories, and for each sample, the RMSD between the modelled $\delta_{h, j}$ and $\delta_{h}^{\exp }$ was calculated. Averages of RMSD were computed for each $D_{s}$ category, while comparisons between the models were performed using the Student $t$-method (Dagnelie 1970). The statistical software Minitab ${ }^{\circledR}$ 15.1.0.0. (Minitab Inc., State College, Pennsylvania, USA) was used for this analysis.

\subsection{Determination of the Correction Factor}

The correction factors $(\varepsilon)$ were evaluated for each model of water vapour transfer function using Eq. 3, and found to depend clearly on the choice of the reference cospectrum. As discussed earlier, we used the experimental STF cospectrum for this purpose. The STF cospectra were computed for each sample using the same method as for $\mathrm{CO}_{2}$ and water vapour fluxes. The cospectra were normalised (Stull 1988) and their mean was computed for each site. These were used in models to compute the correction factor.

\section{Results and Discussion}

\subsection{Experimental Transfer Function}

Figure 2 represents the averaged $\delta_{h}^{\text {exp }}$ (Fig. 2a, b) and $\delta_{c}^{\text {exp }}$ (Fig. 2c, d) obtained for each $D_{s}$ class at Vielsalm (Fig. 2a, c) and Lonzée (Fig. 2b, d). These data were obtained from the
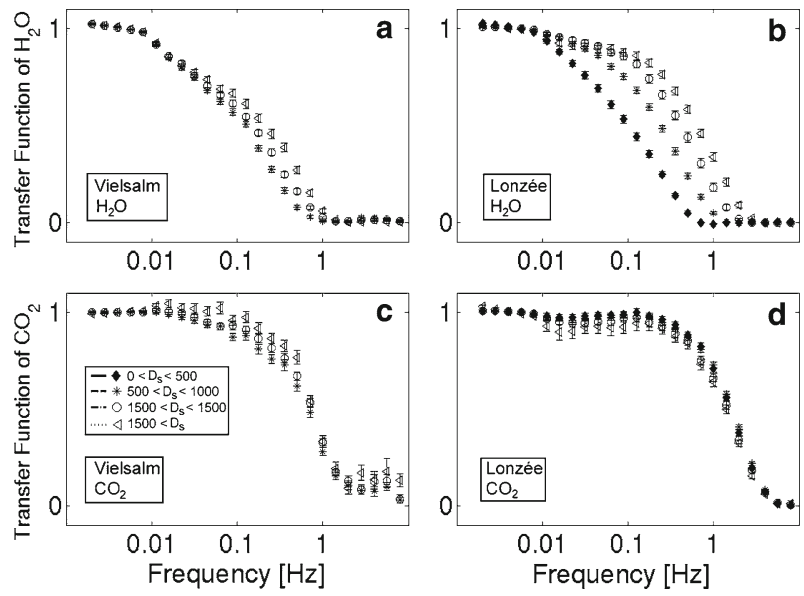

Fig. 2 Experimental transfer functions of the calibration dataset averaged by categories of vapour pressure deficit $\left(D_{s}\right)$. Transfer functions from water vapour fluxes and from $\mathrm{CO}_{2}$ fluxes at the Vielsalm site and at the Lonzée site (Filled diamonds $D_{s}<500 \mathrm{~Pa}$; asterisks $D_{s}$ between 500 and 1,000 Pa; circles $D_{s}$ between 1,000 and $1,500 \mathrm{~Pa}$ and triangles $\left.D_{s}>1,500 \mathrm{~Pa}\right)$ 
calibration set at both sites, and the number of data retained in each class for each model is shown in Tables 1 and 2. At Vielsalm (Lonzée), this number was always larger than 60 (33), confirming that the number of samples was sufficient to obtain statistically representative results, except for $D_{s}<500 \mathrm{~Pa}$ at Vielsalm, which had only four samples. This underlines the need for a large dataset to perform this type of analysis. These figures clearly show the difference in behaviour between $\delta_{c}$ and $\delta_{h}$, and it is clear that the shape of the two transfer functions is not similar: firstly $\delta_{h}$ decreases with a lower slope than $\delta_{c}$, and secondly the $\delta_{h}$ decrease begins at a lower frequency than that of $\delta_{c}$. Finally $\delta_{c}$ is practically insensitive to $D_{s}$ while $\delta_{h}$ clearly depends on this variable, its half-power frequency being reduced by a factor of about 2 between dry $\left(D_{s}>1,500 \mathrm{~Pa}\right)$ and wet $\left(500>D_{s}>1,000 \mathrm{~Pa}\right)$ conditions at Vielsalm, and by a factor of 10 between dry $\left(D_{s}>1,500 \mathrm{~Pa}\right)$ and wet $\left(D_{s}<500 \mathrm{~Pa}\right)$ conditions at Lonzée. This last result confirms that the high frequency attenuation of water vapour fluctuations increases during wet periods, as reported by Clement (2004); Ibrom et al. (2007), Massman and Ibrom (2008) and Mammarella et al. (2009).

\subsection{Modelled Transfer Function}

The values of the regression parameters between the optimised half-power frequency or exponent and $D_{s}$ are given in Tables 3 and 4 for Vielsalm and Lonzée, respectively. Some regressions ( $x_{3}$ vs $D_{s}$ at Lonzée, $f_{o, c, 4}$ vs $D_{s}$ at both sites) did not converge because the trend was not significant. These values were therefore fixed at their mean value in these cases. The modelled $\delta_{h, j}$ are given for four $D_{s}$ classes in Figs. 3 and 4 (lines), as well as $\delta_{h}^{\exp }$ averaged for the same classes (points). The modelled $\delta_{h, j}$ were built by combining Eqs. 7, 8, 10 and 11 with Eq. 10 to 13 and using the values in Tables 3 and 4. The four models render the dependence of the transfer function with $D_{s}$, the half-power frequency decreasing with decreasing $D_{s}$. The half-power frequency values varied from $0.2 \mathrm{~Hz}$ at $500 \mathrm{~Pa}$ to $0.8 \mathrm{~Hz}$ at $2500 \mathrm{~Pa}$ at Lonzée and from $0.1 \mathrm{~Hz}$ at $500 \mathrm{~Pa}$ to $0.25 \mathrm{~Hz}$ at $2500 \mathrm{~Pa}$ at Vielsalm. The difference between the half-power frequencies at the two sites probably results from a difference between the experimental set-ups. This was corroborated by the larger time lag between water vapour

Table 3 Values of parameters for regressions between half-power frequencies $(a, b)$, exponents $(g, i$ and $k)$ and vapour pressure deficit $\left(D_{S}\right)$ at the Vielsalm site

\begin{tabular}{lllll}
\hline Parameters & Model 1 (Gaussian) & Model 2 (Lorentzian) & Model 3 (Eq. 10) & Model 4 (Eq. 11) \\
\hline$a_{j}$ & $8.7 \times 10^{-5} \pm 2.2 \times 10^{-5}$ & $7.0 \times 10^{-5} \pm 1.8 \times 10^{-5}$ & $6.4 \times 10^{-5} \pm 1.7 \times 10^{-5}$ & $10.4 \times 10^{-5} \pm 2.8 \times 10^{-5}$ \\
$b_{j}$ & $0.058 \pm 0.028$ & $0.054 \pm 0.023$ & $0.067 \pm 0.022$ & $0.050 \pm 0.035$ \\
$g_{j}$ & - & - & $-11.7 \times 10^{-5} \pm 5.3 \times 10^{-5}$ & $0.61 \pm 0.50$ \\
$i_{j}$ & - & - & $0.977 \pm 0.068$ & $0.0015 \pm 0.0019$ \\
$k_{j}$ & - & - & - & $0.63 \pm 0.14$ \\
\hline
\end{tabular}

Table 4 Same as Table 3 for the Lonzée site

\begin{tabular}{lllll}
\hline Parameters Model 1 (Gaussian) & Model 2 (Lorentzian) & Model 3 (Eq. 10) & Model 4 (Eq. 11) \\
\hline$a_{j}$ & $33.4 \times 10^{-5} \pm 2.9 \times 10^{-5}$ & $28.8 \times 10^{-5} \pm 2.6 \times 10^{-5}$ & $28.5 \times 10^{-5} \pm 2.6 \times 10^{-5}$ & $28.5 \times 10^{-5} \pm 2.0 \times 10^{-5}$ \\
$b_{j}$ & $0.011 \pm 0.028$ & $0.013 \pm 0.026$ & $0.026 \pm 0.028$ & $1.50 \pm 0.28$ \\
$d_{j}$ & - & - & - & $0.057 \pm 0.053$ \\
$g_{j}$ & - & - & - & $-9.7 \times 10^{-5} \pm 7.3 \times 10^{-5}$ \\
$i_{i}$ & - & - & - & $1.060 \pm 0.069$ \\
\hline
\end{tabular}




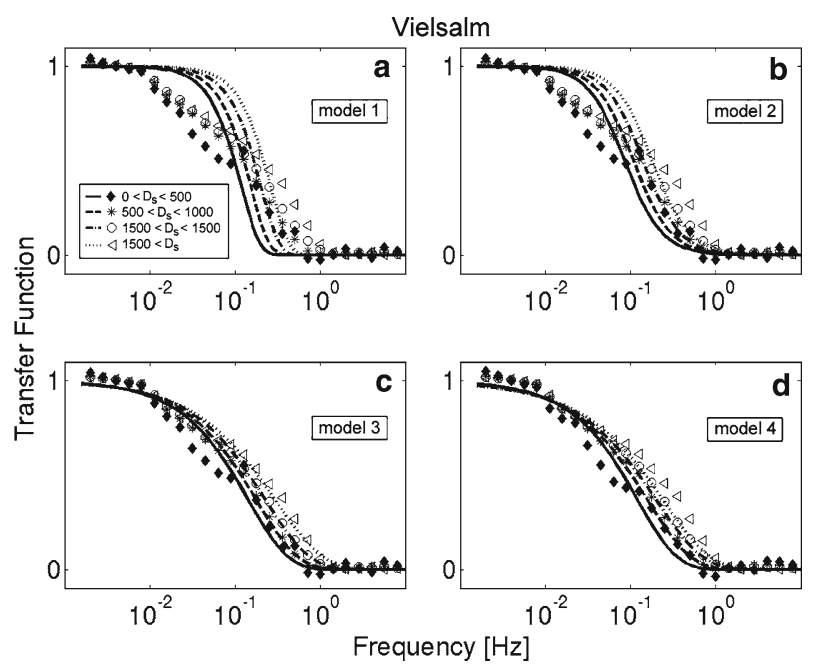

Fig. 3 Superimposition of the experimental and modelled transfer functions for different categories of vapour pressure deficit $\left(D_{S}\right)$ for the four models 1-4, at the Vielsalm site. For $D_{s}$ categories of 0-500, 500-1,000, 1,000-1,500 and above 1,500 $\mathrm{Pa}$, the experimental transfer functions are represented, respectively, with filled diamonds, asterisks, circles and triangles, and modelled transfer functions are solid, dashed, dash-dot and dotted lines

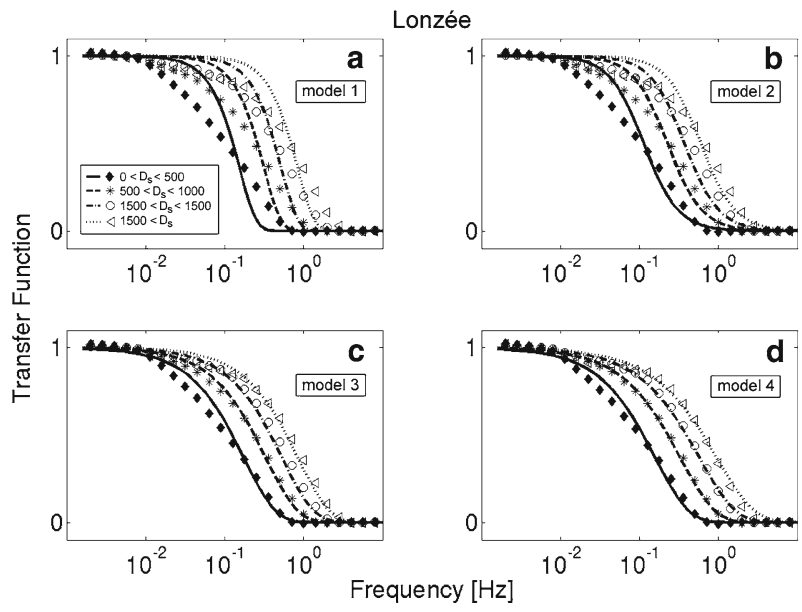

Fig. 4 Same as Fig. 3 for the Lonzée site

and vertical velocity fluctuations and by the lower pressure in the IRGA chamber at Vielsalm when compared to Lonzée. The tube diameters, pumps and filters are identical at the two sites, the only difference being that the tube length is larger at Lonzée than at Vielsalm. However, this would imply a lower half-power frequency, contrary to that observed. We conclude therefore that the most probable reason for the difference was a difference in pump performance, due to different wear. We also found (Figs. 3, 4: a, b) that the classical Gaussian and Lorentzian models did not fit $\delta_{h}^{\text {exp }}$ accordingly, being characterised by a very steep decrease with frequency. These functions therefore underestimate the fluctuation damping in the frequency range $10^{-1}-10^{-2} \mathrm{~Hz}$ and overestimate it above $10^{-1} \mathrm{~Hz}$. The new transfer 
functions clearly provide a better fit at the two sites (Figs. 3, 4: c, d) and are characterised by a less steep decrease, which is also reflected in the lower value of the exponent $x_{j}$. This value is of the order of 1 for both sites and both transfer functions and, in all cases, lower than 2. The fit is not perfect, however: at low $D_{s}$, new models still underestimate $\delta_{h}^{\exp }$ in the range $10^{-1}-10^{-2} \mathrm{~Hz}$, although this is of limited impact because fluxes corresponding to this $D_{s}$ class are generally small.

\subsection{Validation}

The results of the validation are presented in Tables 5 and 6, where the averaged RMSD between modelled $\delta_{h, j}$ and $\delta_{h}^{\text {exp }}$ are given for each model and each $D_{s}$ class. In order to allow a comparison between models, we present the RMSD computed for the $\delta_{h, 1}$ in the same $D_{s}$ class. Underlined values indicate the best model for each $D_{s}$ category. When the differences between RMSD are not significant ( $p$-value: $p>0.05$ ) several models can be selected, confirming that new models best fit the data in each $D_{s}$ class. The fit quality is the same for the two new models at both sites, except at Vielsalm for large $D_{s}$, where $\delta_{h, 3}$ is significantly better than $\delta_{h, 4}$. The difference between the classical and new model fit qualities is larger at high $D_{s}$ at Vielsalm and at low $D_{s}$ at Lonzée. The fit improvement, with reference to $\delta_{h, 1}$, is 41 and $36 \%$ for $\delta_{h, 3}$ and $\delta_{h, 4}$ at $D_{s}>1,500 \mathrm{~Pa}$, and 27 and $31 \%$ at smaller $D_{s}$ at Vielsalm. In contrast, at Lonzée, the new model transfer functions show an improvement of 33 and 34\% at low $D_{s}$, and only 13.7 and $13.9 \%$ at high $D_{s}$. This difference in behaviour is due to the different $\delta_{h}^{\exp }$ shapes at the two sites. At Lonzée, $\delta_{h}^{\exp }$ has a steeper slope than at Vielsalm, so that the improvement in the fit when using new model transfer functions is more important in the latter case.

\subsection{Correction Factors}

The correction factors, $\varepsilon_{s}$, were computed by using Eq. 3, where again the STF cospectrum is used as a substitute for the $w s$ cospectrum. As well, theoretical Kaimal cospectra (Kaimal

Table 5 Averages of the RMSD between experimental and modelled transfer functions at the Vielsalm site

\begin{tabular}{lllll}
\hline$D_{s}$ categories (Pa) & Model 1 (Gaussian) & Model 2 (Lorentzian) & Model 3 (Eq. 10) & Model 4 (Eq. 11) \\
\hline $0-500$ & 0.0242 & 0.0206 & $0.0175^{*}$ & $\underline{0.0166^{*}}$ \\
$500-1,000$ & 0.0198 & 0.0165 & $\underline{0.0133^{*}}$ & $0.0133^{*}$ \\
$1,000-1,500$ & 0.0209 & 0.0174 & $0.0129^{*}$ & $\underline{0.0127^{*}}$ \\
$>1,500$ & 0.0209 & 0.0178 & $\underline{0.0122}$ & 0.0133 \\
\hline
\end{tabular}

Underlined values correspond to the minimum averaged RMSD in each category of vapour pressure deficit $\left(D_{s}\right)$. Asterisks refer to values that are not significantly different from this minimum

Table 6 Same as Table 5 for at the Lonzée site

\begin{tabular}{lllll}
\hline$D_{s}$ categories (Pa) & Model 1 (Gaussian) & Model 2 (Lorentzian) & Model 3 (Eq. 10) & Model 4 (Eq. 11) \\
\hline $0-500$ & 0.0175 & 0.0140 & $0.0117^{*}$ & $\underline{0.0115^{*}}$ \\
$500-1,000$ & 0.0163 & 0.0140 & $\underline{0.0124^{*}}$ & $0.0128^{*}$ \\
$1,000-1,500$ & 0.0155 & 0.0133 & $\underline{0.0117^{*}}$ & $0.0115^{*}$ \\
$>1,500$ & 0.0174 & $0.0159^{*}$ & $0.0150^{*}$ & $\underline{0.0150^{*}}$ \\
\hline
\end{tabular}




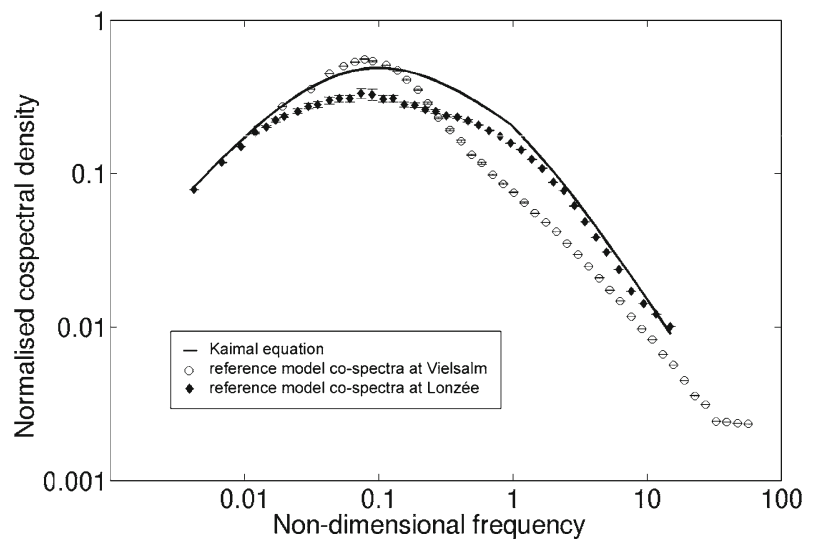

Fig. 5 Normalised Kaimal equation (line), normalised reference model cospectra and their variability at Vielsalm (empty circles) and at Lonzée (filled diamonds) built by the averaged normalised STF cospectra. The $x$-axis is the normalised frequency: $f z / \bar{u}$. The $y$-axis is the normalised cospectral density: $f C_{w T} / \overline{w^{\prime} T^{\prime}}$

and Finnigan 1994) may be used as experimental copectra to this end. In order to evaluate each choice, we computed Lonzée and Vielsalm average heat cospectra and compared them with the Kaimal cospectra. The results are given in Fig. 5. As the Lonzée cospectrum is similar to the theoretical one, particularly in terms of the decrease following a $-4 / 3$ law at high frequency, the Vielsalm cospectrum clearly diverges from it, being characterised by a steeper decrease in the inertial sub-range. This difference can probably be explained by the surface characteristics. The Lonzée site is fairly homogeneous and flat, and so is close to the ideal surface that the Kaimal cospectrum represents. In contrast, Vielsalm is a tall forest, rougher and irregular. The particular shape of the cospectrum probably reflects a short cut in the Kolmogorov cascade (Amiro 1990) that could be due to the presence of trunks or to the development of rolls close to the canopy surface. In any case, this comparison suggests that it is more relevant to base correction factor computations on experimental cospectra rather than on theoretical cospectra. It is also to be noted that the good shape of the Lonzée averaged heat cospectra at high frequency shows minor effects of fluctuation attenuation due to electronic response time or path averaging of the sonic anemometer. The response of correction factors to $D_{s}$ is given for the two sites in Fig. 6. For comparative purposes, the correction factors were computed separately for the four models. In addition, their random uncertainty was deduced from each model parameter uncertainty using a Monte Carlo analysis. The computation was made by setting the wind speed at its average value of $2.5 \mathrm{~m} \mathrm{~s}^{-1}$ at Vielsalm and $2.6 \mathrm{~m} \mathrm{~s}^{-1}$ at Lonzée. It is clear that all the correction factors decreased with increasing $D_{s}$, which was expected in view of the transfer functions. In addition, the correction factors computed on the basis of models 3 and 4 are systematically higher than those computed using the classical models. The correction is on average 10 and 5\% higher at Vielsalm and Lonzée respectively, showing that the impact of the transfer function shape on the fluxes is significant, inducing an increase in their correction compared to the classical transfer functions, even when the latter are adjusted according to $D_{s}$. It should also be noted that the uncertainty (shown in Fig. 6 by the vertical bars) in the correction factor is larger when computed with new models than with the classical ones. This is because the new models are based on a larger number of parameters. The uncertainty is about $2-3 \%$ between 1,000 and $2,000 \mathrm{~Pa}$ and may reach $7 \%$ at 2,500 and $15 \%$ below $500 \mathrm{~Pa}$. The large uncertainty at low $D_{s}$ makes $\varepsilon_{h}$ very uncertain 


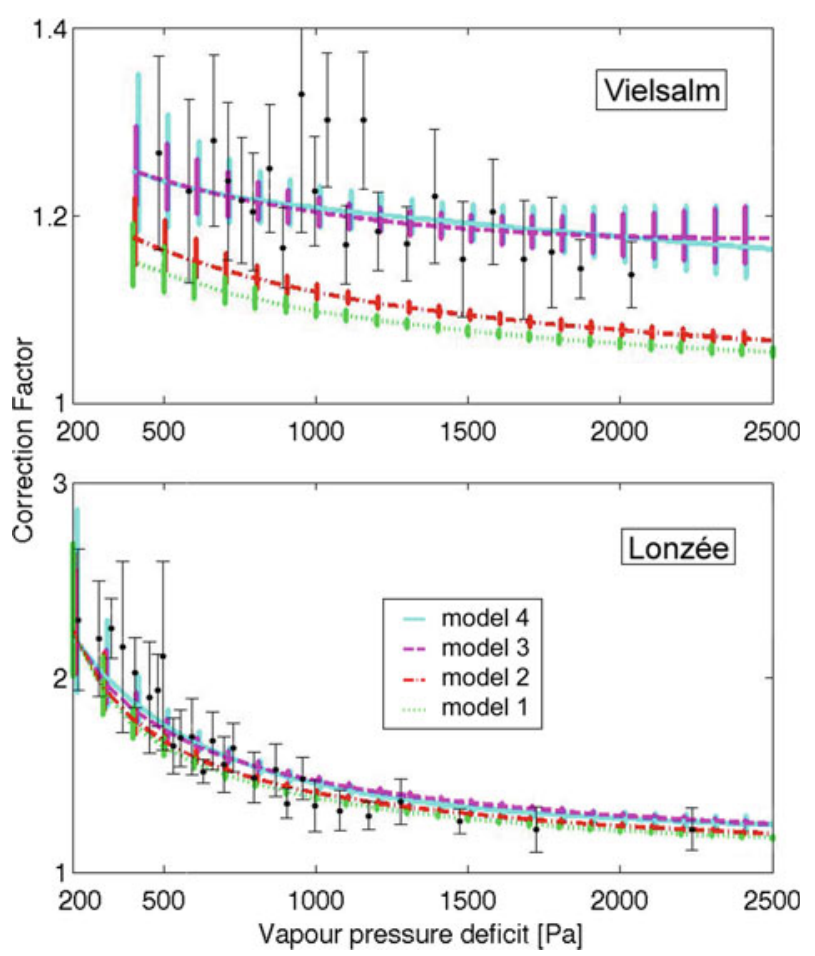

Fig. 6 Comparison of the response to vapour pressure deficit of the water vapour flux correction factors $\left(\varepsilon_{h}\right)$ for the four models (curves) with their standard error and the experimental $\varepsilon_{h}$ (points), at Vielsalm and at Lonzée. Modelled $\varepsilon_{h}$ were determined using an average wind speed of $2.5 \mathrm{~ms}^{-1}$ at Vielsalm and $2.6 \mathrm{~m} \mathrm{~s}^{-1}$ at Lonzée. Experimental $\varepsilon_{h}$ were determined with measured latent heat and STF cospectra (dotted green line model 1, dash-dot red line model 2, dashed magenta line model 3, solid cyan line model 4, points experimental $\left.\varepsilon_{h}\right)$

in this $D_{s}$ range. The model becomes very dependent on the intercept of the relationship between half-power frequency and $D_{s}\left(b_{3}\right.$ and $\left.b_{4}\right)$, which is not well-defined. As a result, it is not clear whether the large $\varepsilon_{h}$ increase towards low $D_{s}$ is significant. However, this is not critical because the latent heat fluxes are generally very small in this $D_{s}$ range. In addition, the uncertainty increase in the high $D_{s}$ range is more important because it affects the expected larger fluxes. It is worth noting, however, that this uncertainty is random and that its impact diminishes with the number of samples. Finally, Fig. 7 presents the response to $D_{s}$ of the correction factor computed with $\varepsilon_{h, 3}$ for different classes of wind speed at Vielsalm and Lonzée. This confirms that the correction factor increases with wind speed. At Lonzée in particular it varies from $11 \pm 1 \%$ at $1 \mathrm{~m} \mathrm{~s}^{-1}$ to $31 \pm 2 \%$ at $4 \mathrm{~m} \mathrm{~s}^{-1}$ for high $D_{s}(2,800 \mathrm{~Pa})$, and from $60 \pm 10 \%$ at $1 \mathrm{~m} \mathrm{~s}^{-1}$ to $166 \pm 28 \%$ at $4 \mathrm{~m} \mathrm{~s}^{-1}$ for low $D_{s}(200 \mathrm{~Pa})$. At Vielsalm, it varies from $22 \pm 6 \%$ at $1 \mathrm{~m} \mathrm{~s}^{-1}$ to $41 \pm 8 \%$ at $4 \mathrm{~m} \mathrm{~s}^{-1}$ for high $D_{s}(2600 \mathrm{~Pa})$, and from $25 \pm 4 \%$ at $1 \mathrm{~m} \mathrm{~s}^{-1}$ to $91 \pm 15 \%$ at $4 \mathrm{~m} \mathrm{~s}^{-1}$ for low $D_{s}(200 \mathrm{~Pa})$.

\section{Conclusions}

Our study shows that classical (Gaussian and Lorentzian) transfer functions are not appropriate for correcting water vapour fluxes. Since their slope is too steep, they do not account 


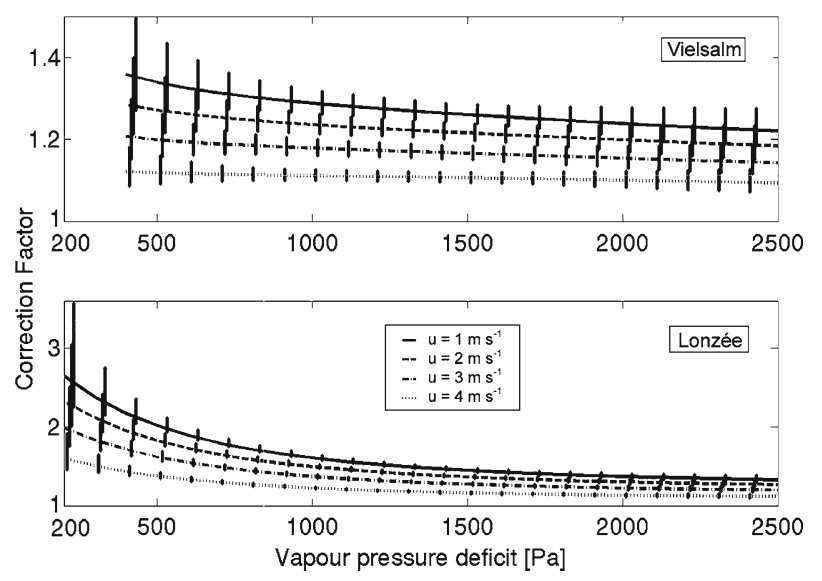

Fig. 7 Relationship between the frequency correction factors with standard error and the vapour pressure deficit for different wind speeds $(u)$ at Vielsalm and at Lonzée (Dotted line $u=1 \mathrm{~m} \mathrm{~s}^{-1}$, dash-dot line $u=2 \mathrm{~m} \mathrm{~s}^{-1}$, dashed line $u=3 \mathrm{~ms}^{-1}$, solid line $u=4 \mathrm{~ms}^{-1}$ )

for the signal attenuation at intermediate frequencies (i.e., between $10^{-2}$ and $10^{-1} \mathrm{~Hz}$ ). Such attenuation is observed for water vapour fluxes but not for $\mathrm{CO}_{2}$ fluxes, suggesting that it results from a process specific to the former, possibly the sorption/desorption of water vapour on the tube walls of the closed-path system. New transfer function equations, characterised by a smaller slope, have been proposed, and are found to better fit the experimental transfer function and lead to an increased correction factor by $5-10 \%$.

The universality of these functions remains of course to be proved. In particular, we recall that the $\delta_{h}^{\exp }$ computation relies on the hypothesis of spectral similarity between sensible and latent heat, which is not proved at our site. However, the smaller transfer function slope than that predicted by classical functions is observed at two very different sites, one agricultural site with flat topography and homogeneous vegetation cover and one forested site with more complex topography and heterogeneous cover. Both sites had a common instrumental set-up, and so it seems realistic to suggest that the particular behaviour of the transfer function is characteristic of the set-up, that is, the closed-path system. It is also worthwhile to note that this particular transfer function shape is observed for long term measurements, for more than ten years at the forested site and for more than four years at the agricultural site.

The main characteristic of the proposed new equations is that their decrease is slower but begins at lower frequencies. At both sites and for all saturation deficits classes, they better fit the observed water vapour transfer functions than do the classical ones. However, calibration at the two sites shows that their parameterisation is not universal and that a specific calibration is necessary for use at a specific site. The fact that the correction factor based on the new equations is $10 \%$ to $5 \%$ larger at Vielsalm and Lonzée suggests that the classical models underestimate the correction to water vapour fluxes, even when the transfer function response to $D_{s}$ is taken into account. Accounting for the new transfer function would probably result in a decrease in the energy balance residual (Wilson et al. 2002).

This study also highlights the importance of basing the correction factor on experimental rather than on theoretical (Kaimal) cospectra, since at the forested site clear deviations from the Kaimal cospectra were observed.

Acknowledgements This study was conducted within the framework of the IMPECVOC BELSPO (Belgian Science Policy; IMPECVOC contract \# SD/TE/03A) and IMECC (European Commission, IMECC-Contract 
026188) projects. The data used were collected at the Vielsalm and Lonzée sites within the framework of the Carboeurope IP project (European Commission, Carboeurope IP-Contract GOCE-CT-2003-505572). The authors thank M. Yernaux and A. Debacq for site maintenance and Q. Laffineur for data preparation, and an anonymous reviewer for many helpful suggestions.

\section{Appendix 1: Description of the Eddy-Covariance System}

The eddy-covariance system (Aubinet et al. 2001; Moureaux et al. 2006) comprises a threedimensional sonic anemometer with a sampling frequency of $20.8 \mathrm{~Hz}$ (Solent 1012R2; Gill Instruments, Lymington, U.K. at Vielsalm and Solent Research R3; Gill Instruments, Lymington, U.K. at Lonzée), an IRGA that measures scalar concentrations with a sampling frequency of $10 \mathrm{~Hz}$ (LI-COR 6262; LI-COR, Lincoln, Nebraska, U.S.A. at Vielsalm and model LI-COR 7000, LI-COR, Lincoln, Nebraska, U.S.A. at Lonzée), a pump (NO22 AN18, KNF, Village Neuf, France at the Vielsalm and Lonzée sites) that creates a flow of $81 \mathrm{~min}^{-1}$, a 4- mm inner diameter Teflon tube ( $8 \mathrm{~m}$ long at Vielsalm, $12.4 \mathrm{~m}$ at Lonzée) and two filters to prevent IRGA sampling chamber clogging. The first filter (ACRO 50 PTFE $1 \mu \mathrm{m}$; Gelman, Ann Arbor, Michigan, USA) placed at the tube inlet was changed every 2 weeks, while the second filter at the IRGA entrance was replaced each year. The pump performances were estimated by monitoring the pressure fall in the tube between the inlet and the IRGA chamber. This pressure fall was very stable, typically varying within $\pm 5 \%$ only for the whole dataset.

\section{References}

Amiro BD (1990) Drag coefficients and turbulence spectra within three boreal forest canopies. BoundaryLayer Meteorol 52:227-246

Ammann C, Brunner A, Spirig C, Neftel A (2006) Water vapour concentration and flux measurements with PTR-MS. Atmos Chem Phys 6:4643-4651

Anderson DE, Verma SB, Clement RJ, Baldocchi DD, Matt DR (1986) Turbulence spectra of $\mathrm{CO}_{2}$, water vapour, temperature and velocity over a deciduous forest. Agric For Meteorol 38:81-99

Aubinet M, Grelle A, Ibrom A, Rannik Ü, Moncrieff J, Foken T, Kowalski AS, Martin PH, Berbigier P, Bernhofer Ch, Clement R, Elbers J, Granier A, Grünwald T, Morgenstern K, Pilegaard K, Rebmann C, Snijders W, Valentini R, Vesala T (2000) Estimates of the annual net carbon and water exchange of forests: the EUROFLUX methodology. Adv Ecol Res 30:113-175

Aubinet M, Chermanne B, Vandenhaute M, Longdoz B, Yernaux M, Laitat E (2001) Long term carbon dioxide exchange above a mixed forest in the Belgian Ardennes. Agric For Meteorol 108:293-315

Aubinet M, Moureaux C, Bodson B, Dufranne D, Heinesch B, Suleau M, Vancutsem F, Vilret A (2009) Carbon sequestration by crop over a 4-year sugar beet/winter wheat/seed potato/winter wheat rotation cycle. Agric For Meteorol 149:407-418

Baldocchi DD (2003) Assessing the eddy covariance technique for evaluating carbon dioxide exchange rates of ecosystems: past, present and future. Glob Change Biol 9:479-492

Clement R (2004) Mass and energy exchange of a plantation forest in Scotland using micrometeorological methods. PhD Thesis, University of Edinburgh, U.K., $382 \mathrm{pp}$

Cohen J, Cohen P, West SG, Aiken LS (2003) Applied multiple regression/correlation analysis for the behavioral sciences. Lawrence Erlbaum Associates Inc., Mahwah, NJ, 703 pp

Dagnelie P (1970) Théorie et Méthodes Statistiques, vol II. Presses Agronomiques de Gembloux, Gembloux, Belgium, $378 \mathrm{pp}$

Eugster W, Senn W (1995) A co-spectral correction model for measurement of turbulent $\mathrm{NO}_{2}$ flux. BoundaryLayer Meteorol 74:321-340

Foken T, Wichura B (1996) Tools for quality assessment of surface-based flux measurements. Agric For Meteorol 78:83-105

Hiller R, Zeeman MJ, Eugster W (2008) Eddy-covariance flux measurements in the complex terrain of an alpine valley in Switzerland. Boundary-Layer Meteorol 127:449-467 
Horst TW (1997) A simple formula for attenuation of eddy fluxes measured with first-order-response scalar sensors. Boundary-Layer Meteorol 82:219-233

Ibrom A, Dellwik E, Flyvbjerg H, Jensen NO, Pilegaard K (2007) Strong low-pass filtering effects on water vapour flux measurements with closed-path eddy correlation Systems. Agric For Meteorol 147:140-156

Kaimal JC, Finnigan JJ (1994) Atmospheric boundary layer flows: their structure and measurement. Oxford University Press, U.K., 289 pp

Kolle O, Rebmann C (2007) Eddysoft-documentation of a software package to acquire and process eddy covariance data. Technical Reports-Max-Planck-Institute für Biogeochemie, 10, 88 pp

Laitat E, Chermanne B, Portier B (2000) Biomass, carbon and nitrogen allocation in open top chambers under ambient and elevated $\mathrm{CO}_{2}$ and in a mixed forest stand. A Tentative approach for scaling up from the experiments of Vielsalm. In: Ceulemans RJM, Veroustraete F, Gond V, Van Rensbergen JBHF (eds) Forest ecosystem modelling, upscaling and remote sensing. Academic Publishing, The Hague, The Netherlands, pp 33-60

Lenschow DH, Raupach MR (1991) The attenuation of fluctuations in scalar concentrations through sampling tubes. J Geophys Res 96:15259-15268

Leuning R, Judd MJ (1996) The relative merits of open- and closed-path analysers for measurement of eddy fluxes. Glob Change Biol 2:241-253

Leuning R, King KM (1992) Comparison of eddy co-variance measurements of $\mathrm{CO}_{2}$ fluxes by open- and closed-path $\mathrm{CO}_{2}$ analysers. Boundary-Layer Meteorol 59:297-311

Leuning R, Moncrieff J (1990) Eddy-covariance $\mathrm{CO}_{2}$ flux measurements using open-path and closed-path $\mathrm{CO}_{2}$ analyzers-corrections for analyzer water-vapour sensitivity and damping of fluctuations in air sampling tubes. Boundary-Layer Meteorol 53:63-76

Mammarella I, Launiainen S, Gronholm T, Keronen P, Pumpanen J, Rannik U, Vesala T (2009) Relative humidity effect on the high-frequency attenuation of water vapor flux measured by a closed-path eddy covariance system. J Atmos Oceanic Technol 26:1852-1866

Massman WJ (1991) The attenuation of concentration fluctuations in turbulent flow through a tube. J Geophys Res 96(D8):269-273

Massman WJ (2000) A simple method for estimating frequency response corrections for eddy covariance systems. Agric For Meteorol 104:185-198

Massman WJ, Ibrom A (2008) Attenuation of concentration fluctuations of water vapor and other trace gases in turbulent tube flow. Atmos Chem Phys 8:6245-6259

Moncrieff JB, Massheder JM, de Bruin H, Elbers J, Friborg T, Heusinkveld B, Kabat P, Scott S, Soegaard H, Verhoef A (1997) A system to measure surface fluxes of momentum, sensible heat, water vapour and carbon dioxide. J Hydrol 188/189:589-611

Monji N, Inoue M, Hamotani K (1994) Comparison of eddy heat fluxes between inside and above a coniferous forest. J Agric Meteorol 50:23-31

Moore CJ (1986) Frequency response corrections for eddy correlation systems. Boundary-Layer Meteorol 37:17-35

Moureaux C, Debacq A, Bodson B, Heinesch B, Aubinet M (2006) Annual net ecosystem carbon exchange by a sugar beet crop. Agric For Meteorol 139:25-39

Ohtaki E (1985) On the similarity in atmospheric fluctuations of carbon dioxide, water vapor and temperature over vegetated fields. Boundary-Layer Meteorol 32:25-37

Panofsky HA, Dutton JA (1984) Atmospheric turbulence. Wiley, New York, 418 pp

Ruppert J, Thomas C, Foken T (2006) Scalar similarity for relaxed eddy accumulation methods. BoundaryLayer Meteorol 120:39-63

Stull RB (1988) An introduction to Boundary Layer Meteorology. Kluwer, Dordrecht, 666 pp

Su HB, Schmid HP, Grimmond CSB, Vogel CS, Oliphant AJ (2004) Spectral characteristics and correction of long-term eddy-covariance measurements over two mixed hardwood forests in non-flat terrain. Boundary-Layer Meteorol 110:213-253

Wilson K, Goldstein A, Falge E, Aubinet M, Baldocchi D, Berbigier P, Bernhofer C, Ceulemans R, Dolman H, Field C, Grelle A, Ibrom A, Law B, Kowalski A, Meyers T, Moncrieff J, Monson R, Oechel W, Tenhunen J, Valentini R, Verma S (2002) Energy balance closure at FLUXNET sites. Agric For Meteorol 113:223-243

Wyngaard JC, Coté OR (1972) Co-spectral similarity in the atmospheric surface layer. Q J Roy Meteorol Soc 98:590-603 